University of Nebraska - Lincoln

DigitalCommons@University of Nebraska - Lincoln

\title{
The Stagonospora nodorum-wheat pathosystem involves multiple proteinaceous host-selective toxins and corresponding host sensitivity genes that interact in an inverse gene-for-gene manner
}

\author{
Timothy L. Friesen \\ USDA-ARS, timothy.friesen@ars.usda.gov \\ Steven W. Meinhardt \\ North Dakota State University \\ Justin D. Faris \\ USDA-ARS
}

Follow this and additional works at: https://digitalcommons.unl.edu/usdaarsfacpub

Friesen, Timothy L.; Meinhardt, Steven W.; and Faris, Justin D., "The Stagonospora nodorum-wheat pathosystem involves multiple proteinaceous host-selective toxins and corresponding host sensitivity genes that interact in an inverse gene-for-gene manner" (2007). Publications from USDA-ARS / UNL Faculty. 1574.

https://digitalcommons.unl.edu/usdaarsfacpub/1574

This Article is brought to you for free and open access by the U.S. Department of Agriculture: Agricultural Research Service, Lincoln, Nebraska at DigitalCommons@University of Nebraska - Lincoln. It has been accepted for inclusion in Publications from USDA-ARS / UNL Faculty by an authorized administrator of DigitalCommons@University of Nebraska - Lincoln. 


\title{
The Stagonospora nodorum-wheat pathosystem involves multiple proteinaceous host-selective toxins and corresponding host sensitivity genes that interact in an inverse gene-for-gene manner
}

\author{
Timothy L. Friesen ${ }^{1, *}$, Steven W. Meinhardt ${ }^{2}$ and Justin D. Faris ${ }^{1}$ \\ ${ }^{1}$ USDA-ARS, Cereal Crop Research Unit, Red River Valley Agricultural Research Center, 1307 N. 18th Street, Fargo, ND 58105, \\ USA, and \\ ${ }^{2}$ Department of Plant Pathology, North Dakota State University, Walster Hall, Fargo, ND 58105, USA
}

Received 5 March 2007; revised: 11 April 2007; accepted: 27 April 2007.

*For correspondence (fax +1 701239 1369; e-mail timothy.friesen@ars.usda.gov).

\begin{abstract}
Summary
We recently showed that the wheat pathogen Stagonospora nodorum produces proteinaceous host-selective toxins (HSTs). These toxins include SnTox1 as well as SnToxA, a HST first identified from Pyrenophora tritici-repentis that was implicated in a very recent horizontal gene transfer event from $S$. nodorum to $P$. triticirepentis. Compelling evidence implicating SnToxA and SnTox1 in disease development has been obtained. Here, we report the partial purification and characterization of a third HST designated SnTox2, as well as the genetic characterization of the corresponding host-sensitivity gene. SnTox2 was protease sensitive and is estimated between 7 and $10 \mathrm{kDa}$ in size. Sensitivity to SnTox2 was conferred by a single dominant gene designated Snn2, which mapped to the short arm of wheat chromosome 2D. Genetic analysis of reaction to conidial inoculations in a segregating wheat population indicated that both the Snn2-SnTox2 and the Tsn1SnToxA interactions were involved in disease development, and together they accounted for the majority of the phenotypic variation. Therefore, $S$. nodorum produces multiple toxins that rely on specific interactions with host gene products to cause disease. The identification of multiple HST-host gene interactions important for disease development and the availability of the $S$. nodorum whole genome sequence indicate the potential for this pathosystem to serve as a toxin-based, inverse gene-for-gene model.
\end{abstract}

Keywords: host-selective toxin, gene-for-gene, Septoria, Phaeosphaeria, Pyrenophora tritici-repentis, Ptr ToxA.

Introduction

Phaeosphaeria nodorum (E. Mull.) Hedjar (anamorph: Stagonospora nodorum), causal agent of $S$. nodorum blotch (SNB), is a major foliar and glume pathogen of common wheat (Triticum aestivum L.) and durum wheat (T. turgidum L.) throughout the world. S. nodorum has the potential to cause significant yield losses (King et al., 1983; Wicki et al., 1999 ) if given favorable environmental conditions and, as in most plant diseases, host resistance is the most economically effective method of control.

Host-selective toxins (HSTs) have been shown to be important in many host-pathogen systems, including many involving cereals, but have been identified in only a few

Journal compilation @ 2007 Blackwell Publishing Ltd No claim to original US government works genera of fungi. Currently, HSTs are known to be produced by about 20 species, several of which produce multiple toxins (Wolpert et al., 2002). HSTs are important in some plant-fungal interactions because of their specificity in causing disease. The interactions between HSTs and their hosts are very specialized and unlike the classical genefor-gene interaction, sensitivity/susceptibility is usually conferred by a single dominant gene (reviewed in Wolpert et al., 2002). Therefore, HST-host gene interactions are often seen as "inverse gene-for-gene" systems.

To date, ToxA, produced by both Pyrenophora triticirepentis ( $\mathrm{Ptr}$ ToxA) (Tomás et al., 1990) and $S$. nodorum 
(SnToxA) (Friesen et al., 2006), and Ptr ToxB, (Strelkov et al., 1999) produced by $P$. tritici-repentis, are the only proteinaceous HSTs that have been completely purified and characterized. Although purification and characterization have not been completed, Liu et al. (2004a) recently identified and partially purified a proteinaceous HST produced by S. nodorum and designated it SnTox1. Sensitivity to SnTox1 was conditioned by a single dominant gene in the host,

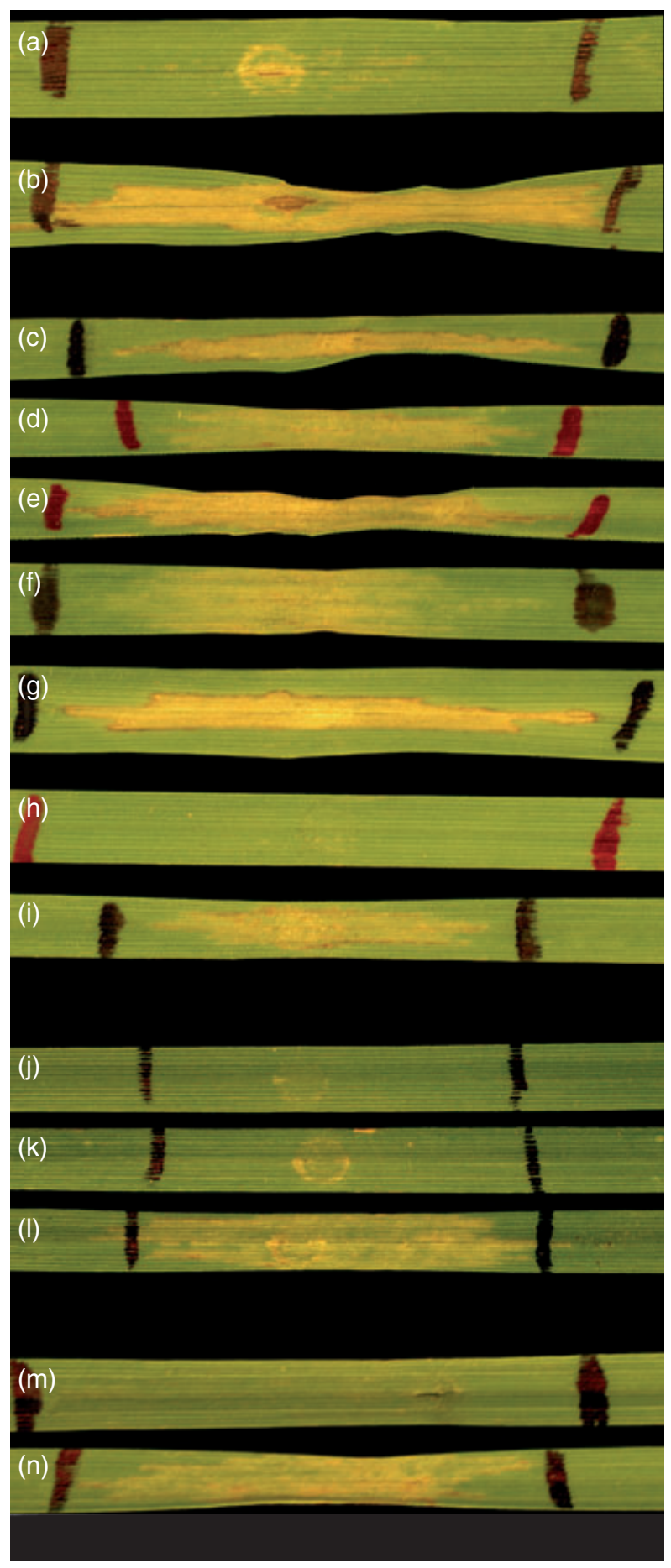

which was designated Snn1 (Liu et al., 2004a). Snn1 was genetically and physically mapped to the distal end of the short arm of chromosome 1B (Liu et al., 2004a) using the International Triticeae Mapping Initiative population and wheat chromosome deletion stocks (Endo and Gill, 1996), respectively. More recently, the Ptr ToxA-like gene SnToxA was identified in $S$. nodorum and SnToxA was shown to interact with Tsn 1, the same host gene targeted in the Ptr ToxA host-pathogen interaction (Friesen et al., 2006). Using QTL analysis, the interaction of the Tsn 1 locus with SnToxA was found to play a major role in the development of SNB on wheat (Liu et al., 2006), and site-directed gene disruption of SnToxA and the transformation of avirulent $S$. nodorum isolates with the ToxA gene were shown to significantly reduce and increase disease, respectively, on lines containing Tsn 1 (Friesen et al., 2006).

Host-selective toxins in the $S$. nodorum system have been shown to be major factors in disease development. And, although they are considered virulence factors, aiding the pathogen in disease development rather than true pathogenicity factors, which define their host range, these toxins are host selective in nature because of their host genotype specificity involving single host sensitivity genes. Here, we report the identification of a third proteinaceous HST produced by $S$. nodorum, the identification and chromosomal location of the host gene conditioning sensitivity to the toxin, the role of the toxin in disease development, and the identification of QTL associated with seedling resistance to the SnToxA and SnTox2 producing S. nodorum isolate Sn6.

\section{Results}

\section{Identification of HSTs produced by Sn6}

Culture filtrates of Sn6 were prepared and infiltrated into leaves of the hard red spring wheat cultivars BR34 and Grandin, which are the parents of the BR34 $\times$ Grandin (BG) recombinant inbred (RI) mapping population (hereafter referred to as the BG population). Infiltrated leaves of Grandin developed extensive necrosis (cell death) throughout the site of infiltration, whereas no reaction was observed on infiltrated leaves of BR34 (Figure 1). Individuals of the

\footnotetext{
Figure 1. Infiltration reaction of parental lines BR34 (a) and Grandin (b) infiltrated with culture filtrates of Stagonospora nodorum isolate Sn6. Leaves of the BR34 $\times$ Grandin (BG) populate live BG223 (SnTox2 sensitive) were infiltrated with samples containing active SnTox2 subjected to ultra filtration. These samples included a $30 \mathrm{kDa}$ concentrate (c), a $30 \mathrm{kDa}$ filtrate (d), a $10 \mathrm{kDa}$ concentrate (e), a $10 \mathrm{kDa}$ filtrate (f), a $3 \mathrm{kDa}$ concentrate (g) a $3 \mathrm{kDa}$ filtrate (h) and an untreated SnTox2 control (i). Fractions containing active SnTox2 were treated with Pronase (j) and infiltrated into leaves of line BG223 to verify that SnTox2 was a proteinaceous toxin. Pronase only (k) and untreated SnTox2 (I) were also infiltrated into leaves of line BG223 and were used as controls. Light dependency of the reaction was shown by infiltrating active fractions of SnTox2 into leaves of line BG223 and placing plants in either a $48 \mathrm{~h}$ dark period $(\mathrm{m})$ or a $12 \mathrm{~h}$ photoperiod $(\mathrm{n})$ each for $48 \mathrm{~h}$.
} 


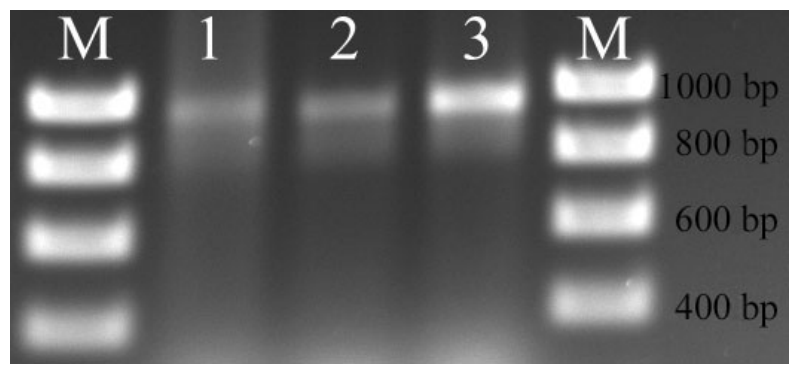

Figure 2. Polymerase chain reaction amplification of the ToxA gene from a control genomic clone of the complete ToxA gene from Stagonospora nodorum (lane 1), and S. nodorum isolates Sn6 (lane 2), and Sn2000 (lane 3) (Friesen et al., 2006). Lanes 1-3 are flanked by size standards (lane M) ranging from 400 to $1000 \mathrm{bp}$. Primers were designed to amplify a $965 \mathrm{bp}$ fragment from the ToxA gene.

entire BG population were subsequently infiltrated with Sn6 culture filtrate, and three days after infiltration, lines exhibited either extensive necrosis throughout the site of infiltration, or essentially no reaction. The BG population segregated for reaction to the culture filtrate in a ratio of 89 sensitive: 29 insensitive, which is not significantly different from the expected $3: 1$ ratio $\left(\chi^{2}=0.011, P=0.92\right)$ for two independent host genes conferring sensitivity. This suggested that Sn6 culture filtrates contained at least two toxins. The $29 \mathrm{RI}$ lines insensitive to the $\mathrm{Sn} 6$ culture filtrate were also known to be insensitive to SnToxA (Liu et al., 2006), which led us to hypothesize that one of the two toxins produced by Sn6 may be SnToxA. Subsequent PCR analysis of Sn6 with SnToxA gene-specific primers showed that Sn6 carried the SnToxA gene (Figure 2). The expression of SnToxA by $\mathrm{Sn} 6$ was later confirmed by QTL analysis (see section The role of SnTox2 and SnToxA in disease caused by S. nodorum isolate $\mathrm{Sn6}$ ).

Therefore, the $S$. nodorum isolate Sn6 produces at least two necrosis-inducing, HSTs in culture. The first toxin was designated SnToxA and described by Friesen et al. (2006). The partial purification, initial characterization, and analysis of the second toxin, which we propose to designate SnTox2, are described below.

\section{Partial purification of SnTox2}

Dialyzed Sn6 culture filtrates were subjected to ion exchange chromatography using a $10 \mathrm{ml}(1.6 \times 5 \mathrm{~cm}) \mathrm{S}$-Sepharose Fast Flow column (GE Healthcare, Piscataway, NJ, USA). SnTox2 activity eluted between 130 and $160 \mathrm{~mm} \mathrm{NaCl}$ as determined by bioassays on the SnTox2 sensitive wheat line BG223. Under the same conditions SnToxA eluted between 80 and $100 \mathrm{~mm} \mathrm{NaCl}$. At this stage of purification SnTox2 was purified at least 14 fold based on the $280 \mathrm{~nm}$ absorption of all proteins bound to the column relative to the absorption found in the fractions used for testing or further purification. Fractions obtained from ion exchange containing SnTox2 were tested on the SnToxA differential line BG261 to verify complete separation. No necrosis was observed indicating that SnToxA was not present in the partially purified SnTox2 sample. In some experiments the concentrated active fractions from ion exchange were then further purified based on size using a Superose 12 HR 10/30 gel filtration column (Pharmacia). A 70-fold level of purification is conservatively estimated based on crude analysis of chromatograms of ion exchange and gel filtration chromatography.

\section{Reaction of the BG population to partially purified SnTox2 and identification of the host sensitivity gene}

The partial purification of SnTox2 using the $10 \mathrm{ml}$ $(1.6 \times 5 \mathrm{~cm})$ S-Sepharose Fast Flow column (Pharmacia) alone allowed us to separate SnTox2 from SnToxA and evaluate the genetic segregation of sensitivity to each toxin independently. The entire BG population and parents were infiltrated with partially purified SnTox2. As with the culture filtrate, infiltration of partially purified SnTox2 into leaves of Grandin resulted in severe necrosis, but no reaction was observed in BR34. Infiltration of the BG population with partially purified SnTox 2 resulted in a segregation ratio of 60 sensitive: 58 insensitive, which was not significantly different $\left(\chi^{2}=0.03, P=0.90\right)$ from the expected $1: 1$ ratio for a single gene (Table 1). This provided additional verification that the purified SnTox2 cultures contained only SnTox 2 and not SnToxA.

$F_{1}$ and $F_{2}$ individuals derived from BR34 $\times$ Grandin were infiltrated with partially purified SnTox2 to investigate dominance of the gene governing sensitivity in the host. $F_{1}$ seedlings were sensitive to SnTox2, and the $F_{2}$ population of 38 individuals segregated in a ratio of 32 sensitive: 6 insensitive, which fit the expected 3:1 (sensitive: insensitive) ratio for a single dominant gene governing sensitivity $\left(\chi^{2}=1.72, P=0.2\right) \quad($ Table 1$)$. We propose the symbols Snn2 and snn2 to designate the alleles governing sensitivity and insensitivity, respectively, to SnTox2.

Sensitivity to SnToxA was previously shown to be governed by a single dominant gene designated Tsn 1 and the $B G$ population segregated in a ratio of 59 sensitive: 59

Table 1 Genetic analysis of Snn2 in the BR34 X Grandin (BG) $F_{2}$ population and of $T s n 1$ and Snn2 in the BG recombinant inbred (RI) population

\begin{tabular}{llllll}
\hline Population & Genotype & Observed & Expected & $\chi^{2}$ & $P$ \\
\hline BG F & Snn2/_:snn2/snn2 & $32: 6$ & $3: 1$ & 1.72 & 0.2 \\
BG RI & Snn2/Snn2:snn2/snn2 & $60: 58$ & $1: 1$ & 0.03 & 0.9 \\
BG RI & Tsn1/Tsn1:tsn1/tsn1 & $59: 59$ & $1: 1$ & 0.0 & 1.0 \\
BG RI & $T s n 1 / T s n 1 / S n n 2 / S n n 2:$ & $30: 29: 30: 29$ & $1: 1: 1: 1$ & 0.03 & 0.9 \\
& $T s n 1 / T s n 1 / s n n 2 / s n n 2:$ & & & & \\
& $t s n 1 / t s n 1 / S n n 2 / S n n 2:$ & & & & \\
& $t s n 1 / t s n 1 / s n n 2 / s n n 2$ & & & & \\
\hline
\end{tabular}


insensitive for reaction to SnToxA (Liu et al., 2006) (Table 1). Taking this data into account, we were able to classify each RI line according to the genotypic classes Tsn 1/Snn2, Tsn 1/ snn2, tsn1/Snn2, tsn1/snn2, which segregated in a 1:1:1:1 ratio (Table 1) indicating that Tsn1 and Snn2 are independently inherited.

\section{Chromosome localization of Snn2}

Data for the markers used to develop the genetic linkage maps in the BG population was presented in Liu et al. (2005). Linkage analysis of Snn2 genotypic scores indicated that it mapped near the distal end of the short arm of chromosome 2D at an LOD $=9.44$. The microsatellite markers Xgwm614.1 and Xbarc95 flanked Snn2 at genetic distances of 7.6 and $5.9 \mathrm{cM}$, respectively (Figure 3). Comparison between the genetic linkage map and the chromosome deletion linebased physical map (Sourdille et al., 2004) indicated that Snn2 is physically located in deletion bin 2DS5-0.47-1.00, which accounts for the distal $53 \%$ of the chromosome 2D short arm (Figure 3).

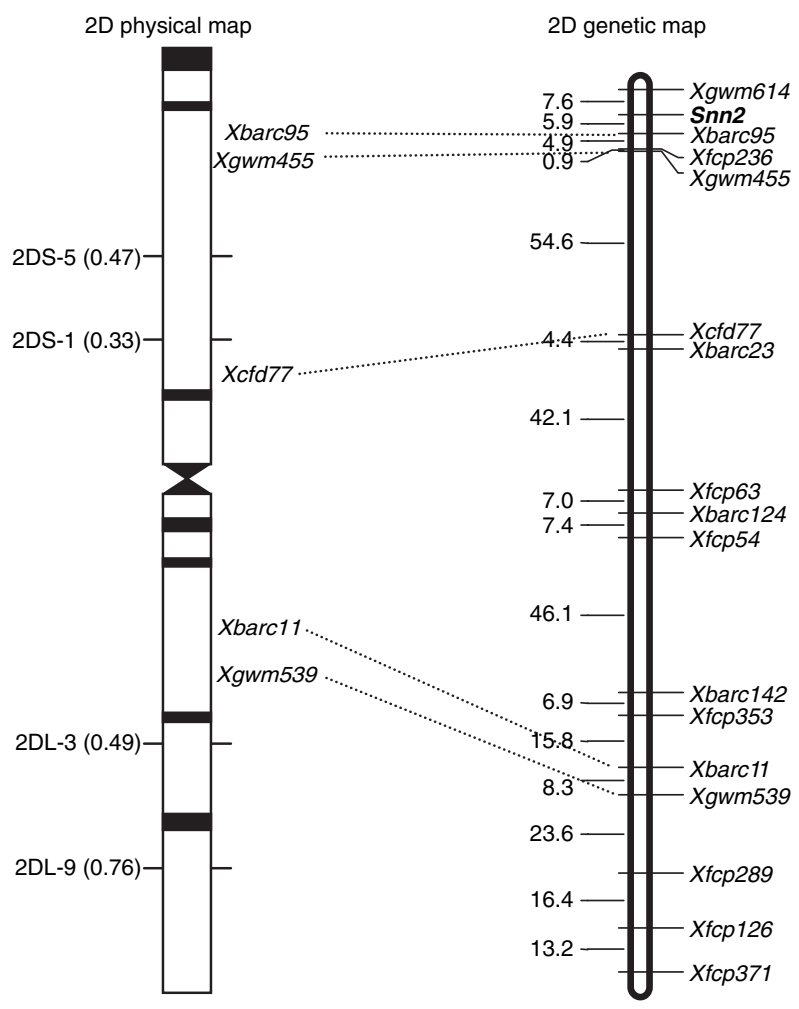

Figure 3. Comparison of common markers between the physical map of chromosome 2D (left) (Sourdille et al., 2004) and the genetic map of 2D generated in the BG population (right). Fraction breakpoints are indicated to the left of the physical map and bin locations of markers to the right. Darkened regions along the physical map represent approximate locations and sizes of cytological C-bands. On the genetic map, cM distances are shown to the left and markers to the right. Dotted lines connect markers in common between the physical and genetic maps.
The role of SnTox2 and SnToxA in disease caused by S. nodorum isolate Sn6

A total of three replications consisting of the BG population and parents planted in a completely randomized design were inoculated with conidia of Sn6. Disease reaction types were rated on a scale of $0-5$ with 0 being the most resistant and 5 the most susceptible. A test for homogeneity of variances among replicates indicated they were not homogeneous at the 0.05 level of probability (Table 2). Because of limitations in greenhouse, mist chamber, and growth chamber space, the three replicates were not inoculated at the same time, which may have been a significant source of variation. However, the three replicates were homogeneous at the 0.01 level of probability and therefore the overall combined means of the three replicates were analyzed as well. Analysis of variance indicated significant differences among $\mathrm{Rl}$ lines as well as among replicates (Table 3 ).

Analysis of the combined mean disease reaction types for the $B G$ population indicated that reaction types ranged from 0.5 to 4.0 (Table 4, Figure 4) with an overall mean of 2.12. Disease reaction types for lines sensitive to SnToxA but not SnTox2 averaged 1.91 whereas lines sensitive to SnTox2 and insensitive to SnToxA averaged 2.30. Lines sensitive to both toxins were significantly more susceptible than those containing sensitivity to only one toxin (Figure 4, Table 4) and lines sensitive to SnTox2 only were significantly more susceptible than lines sensitive to SnToxA only (Figure 4, Table 4). Lines insensitive to both toxins were significantly less susceptible than lines sensitive to either or both toxins (Figure 4, Table 4).

Table 2 Results of the homogeneity of variance analysis among replicates of the BR34 $\times$ Grandin (BG) recombinant inbred population inoculated with Stagonospora nodorum isolate Sn6

\begin{tabular}{lll}
\hline Replicate & Mean & $n$ \\
\hline 1 & $2.29 \mathrm{a}$ & 120 \\
2 & $2.11 \mathrm{ab}$ & 120 \\
3 & $1.95 \mathrm{~b}$ & 120 \\
\hline
\end{tabular}

* Means followed by the same letter are not significantly different at the 0.05 level of probability.

Table 3 Analysis of variance for the combined mean reaction types for the 118 lines of the BR34 $\times$ Grandin (BG) population inoculated with Stagonospora nodorum isolate $\mathrm{Sn} 6$

\begin{tabular}{lrlrc}
\hline Source & d.f. & Mean square & $F$-value & $\operatorname{Pr}>F$ \\
\hline Line & 117 & 2.24 & 8.51 & $<0.0001$ \\
Rep & 2 & 3.48 & 13.22 & $<0.0001$ \\
Error & 234 & 0.26 & & \\
Corrected Total & 353 & & & \\
\hline
\end{tabular}

C.V. $=24.21$ 
Table 4 Average and range of disease reaction types of parents and recombinant inbred lines of the BR34 $\times$ Grandin (BG) population for the four allelic state combinations for Snn2 and Tsn1 after inoculation with conidia of Stagonospora nodorum isolate $\mathrm{Sn} 6$

\begin{tabular}{lll}
\hline Genotype & $\begin{array}{l}\text { Reaction } \\
\text { type range }\end{array}$ & $\begin{array}{l}\text { Average disease } \\
\text { reaction type }\end{array}$ \\
\hline BR34 & $0.0-0.5$ & $0.17 \pm 0.29$ \\
Grandin & 4.0 & $4.00 \pm 0.0$ \\
snn2snn2/tsn1tsn1 & $0.5-2.33$ & $1.16 \mathrm{a}^{*}$ \\
snn2snn2/Tsn1Tsn1 & $0.5-3.17$ & $1.91 \mathrm{~b}^{*}$ \\
Snn2Snn2/tsn1tsn1 & $1.33-3.33$ & $2.30 \mathrm{c}^{*}$ \\
Snn2Snn2/Tsn1Tsn1 & $2.17-4.0$ & $3.07 \mathrm{~d}^{*}$ \\
\hline
\end{tabular}

*Numbers followed by the same letter are not significantly different at the 0.05 level of probability.

QTL analysis was conducted to determine the effects of the Tsn1-SnToxA and Snn2-SnTox2 interactions in disease caused by Sn6. Reaction types of the three replicates as well as the combined phenotypic means were regressed on the genotypic marker data to identify genomic regions associated with resistance to SNB caused by isolate Sn6. Simple linear regression analysis, simple interval mapping, and composite interval mapping (CIM) revealed four OTL significantly associated with resistance to SNB. The OTL with the largest effects for the three replicates and the combined means was detected at the Snn2 locus short arm of chromosome 2D and designated OSnb.fcu-2DS (Table 5, Figure 5). The Snn2 phenotypic marker was the most significant factor underlying this $\mathrm{OTL}$, and resistance effects were contributed by BR34, which is insensitive to SnTox2 and carries the recessive snn2 allele. QSnb.fcu-2DS alone explained from $30 \%$ to $49 \%$ of the variation for individual replicates and $47 \%$ of the phenotypic variation for the combined means (Table 5).

Composite interval mapping revealed the second largest QTL on the long arm of chromosome 5B at the Tsn1 locus (Figure 5). The Tsn1 phenotypic marker was the most significant factor underlying this $\mathrm{QTL}$, which was designated QSnb.fcu-5BL and explained $14-20 \%$ of the variation for individual replicates and $20 \%$ of the phenotypic variation for the combined means (Table 5). As with OSnb.fcu-2DS, resistance effects of $Q S n b . f c u-5 B L$ were contributed by BR34, which is insensitive to SnToxA and carries the tsn 1 allele. Therefore, the two toxin-insensitivity alleles, snn2 and tsn1, each underlie QTL associated with resistance to isolate Sn6, which produces both SnTox2 and SnToxA.

A third QTL at the distal end of the long arm of chromosome $5 \mathrm{~A}$ most significantly associated with the molecular marker Xfcp13 (Table 5, Figure 5) was identified by CIM. This QTL, designated $Q S n b . f c u-5 A L$, was not significantly associated with resistance to SNB in the first replicate, but explained $13 \%$ and $12 \%$ of the variation in replicates 2 and 3 , respectively, and it explained $10 \%$ of the phenotypic variation using the combined means.

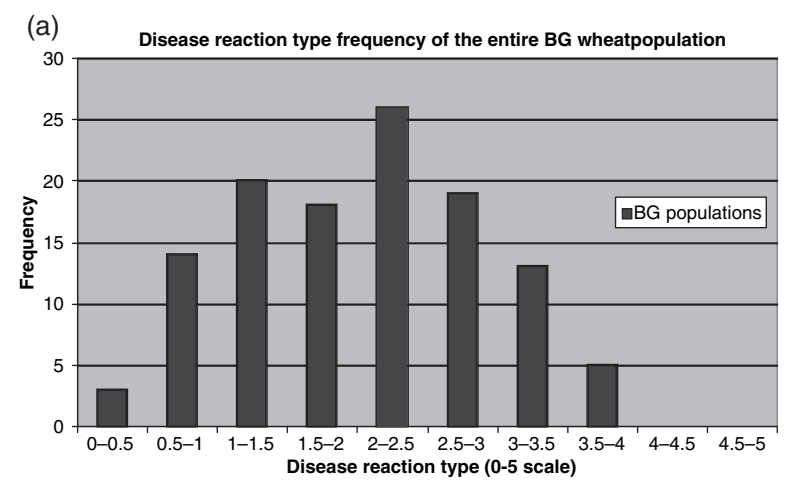

(b) Disease reaction type frequency comparison of BG lines sensitive (Tsn1) and

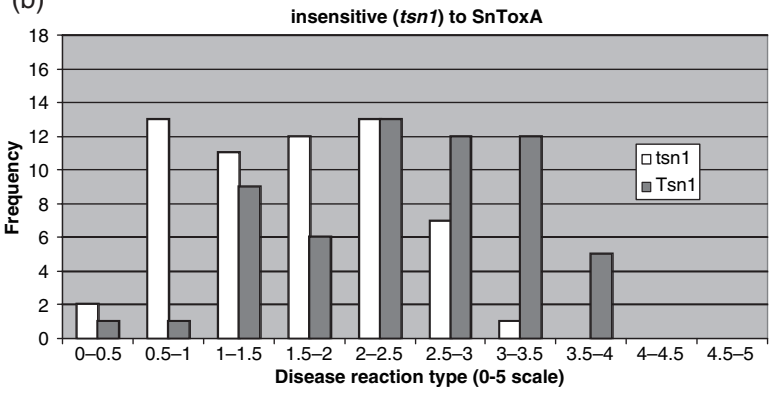

(c) Disease reaction type frequency comparison of BG lines sensitive (Snn2) and

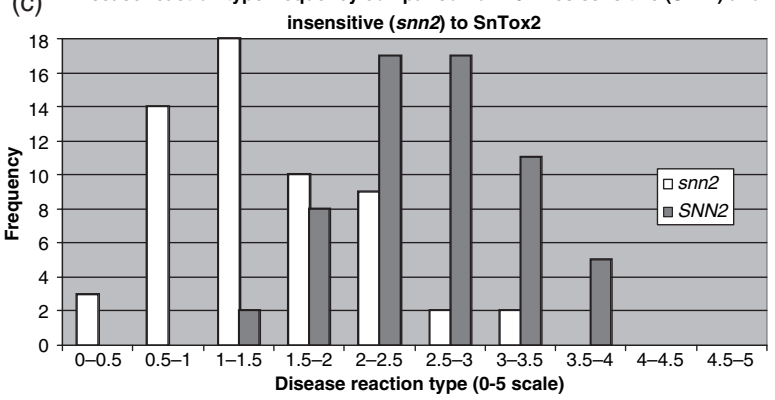

(d) Disease reaction type frequency comparison of BG lines sensitive (Tsn1/Snn1)

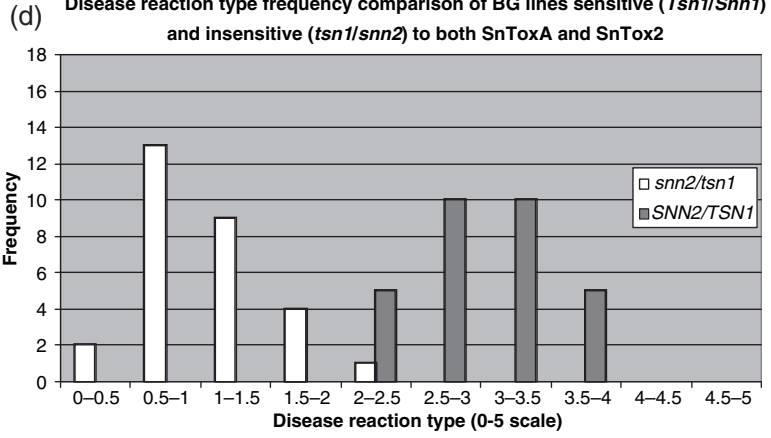

Figure 4. Histograms of average disease reaction types caused by Stagonospora nodorum isolate Sn6 in the BR34 $\times$ Grandin (BG) population. (a) Average disease reaction types across the entire BG population; (b) Average disease reaction types of SnToxA sensitive and insensitive lines; (c) Average disease reaction types of SnTox2 sensitive and insensitive lines; and (d) Average disease reaction types of lines sensitive to both toxins compared to lines insensitive to both toxins.

The fourth QTL was also detected by CIM and was on the short arm of chromosome 1B near the marker Xgdm125 (Table 5, Figure 5). This QTL, designated QSnb.fcu-1BS was 
Table 5 QTL detected for seedling resistance to Stagonospora nodorum blotch caused by isolate Sn6 in the BR34 $\times$ Grandin (BG) recombinant inbred population detected by interval mapping for the three replicates as well as the combined means. The chromosomal locations, associated markers, confidence intervals, $R^{2}, L O D$, and additive effects values are given

\begin{tabular}{|c|c|c|c|c|c|c|c|c|c|c|c|c|c|c|c|c|c|c|}
\hline \multirow{2}{*}{$\begin{array}{l}\text { Chrom. } \\
\text { arm }\end{array}$} & \multirow[b]{2}{*}{ QTL } & \multirow[b]{2}{*}{ Marker } & \multicolumn{4}{|c|}{ C.I. $(\mathrm{cM})^{\mathrm{a}}$} & \multicolumn{4}{|l|}{$R^{2}$} & \multicolumn{4}{|l|}{ LOD } & \multicolumn{4}{|c|}{ Add. effect } \\
\hline & & & R1 & $\mathrm{R} 2$ & R3 & Comb. & $\mathrm{R} 1$ & $\mathrm{R} 2$ & R3 & Comb. & R1 & $\mathrm{R} 2$ & R3 & Comb. & $\mathrm{R} 1$ & $\mathrm{R} 2$ & R3 & Comb. \\
\hline 1BS & QSnb.fcu-1BS & Xgdm 125 & - & - & $6-14$ & $5-12$ & - & - & 0.11 & 0.05 & NS & NS & 6.3 & 3.9 & NS & NS & 0.34 & 0.21 \\
\hline 2DS & QSnb.fcu-2DS & Snn2 & $4-8$ & $3-7$ & $3-10$ & $3-8$ & 0.49 & 0.40 & 0.30 & 0.47 & 16.7 & 12.3 & 8.9 & 15.9 & 0.80 & 0.50 & 0.54 & 0.65 \\
\hline $5 \mathrm{AL}$ & QSnb.fcu-5AL & $X f_{c p} 13$ & - & 177-182 & 173-182 & $173-182$ & - & 0.13 & 0.12 & 0.10 & NS & 5.7 & 4.5 & 5.4 & NS & 0.29 & 0.35 & 0.31 \\
\hline $5 B \mathrm{~B}$ & QSnb.fcu- $5 B L$ & Tsn1 & $74-83$ & $71-88$ & $72-85$ & $74-84$ & 0.16 & 0.14 & 0.20 & 0.20 & 9.6 & 6.3 & 8.1 & 11.8 & 0.51 & 0.32 & 0.45 & 0.43 \\
\hline
\end{tabular}

${ }^{a}$ CentiMorgan position of the $95 \% \mathrm{Cl}$ for the QTL.

NS, non-significant.
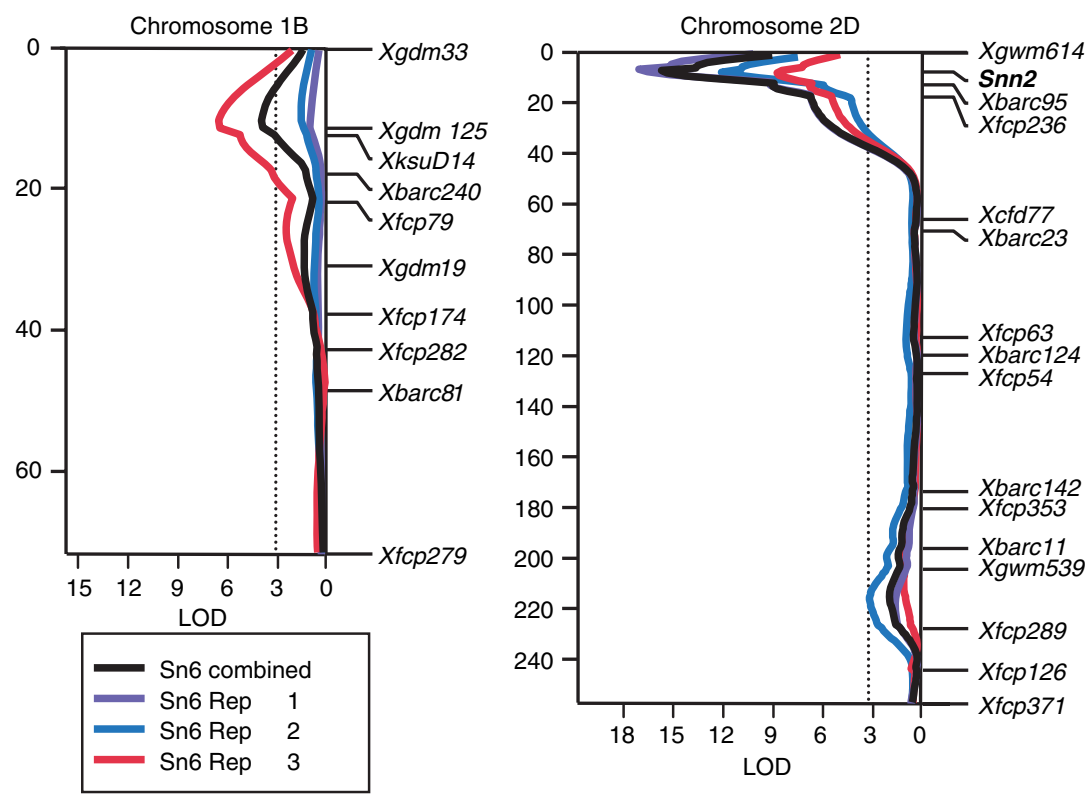

Figure 5. Interval regression maps of chromosomes $1 B, 2 D, 5 A$, and $5 B$, which harbor QTLs for resistance to SNB caused by isolate Sn6. A centiMorgan (cM) scale is indicated to the left of the maps, and the markers are shown in their relative positions along the right. A LOD scale is indicated along the $x$-axis, and the significant LOD threshold of 3.2 is indicated with a dotted line.
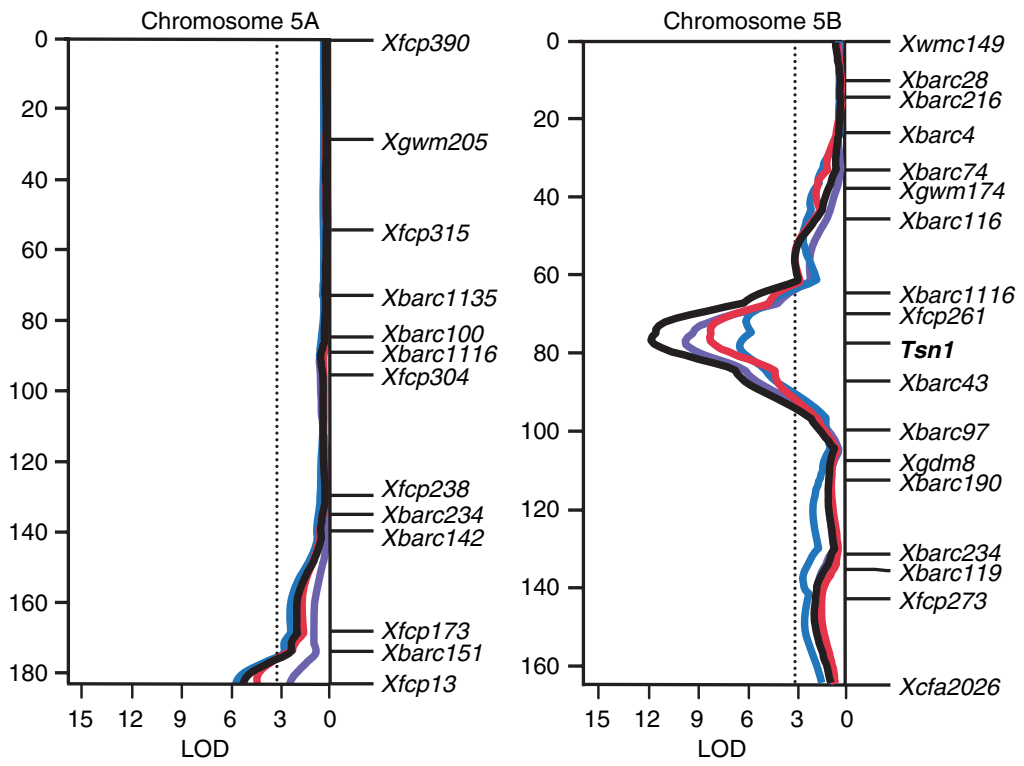

Journal compilation (c) 2007 Blackwell Publishing Ltd, The Plant Journal, (2007), 51, 681-692 No claim to original US government works 
not significantly associated with resistance to Sn6 in replicates 1 and 2, but explained $11 \%$ and $5 \%$ of the phenotypic variation for replicate 3 and the combined means, respectively (Table 5).

The markers most significantly associated with QTLs QSnb.fcu-2DS, OSnb.fcu-5BL, OSnb.fcu-5AL, and QSnb.fcu-1BS were assembled into multiple regression models to determine the total amount of phenotypic variation explained by the markers. For replicate 1, the model consisted of the phenotypic markers Snn2 and Tsn 1 only, which together explained $65 \%$ of the variation. The model for replicate 2 consisted of Snn2, Tsn1, and Xfcp 13 (OSnb.fcu-5AL) and explained $59 \%$ of the variation. The multiple regression models for replicate 3 and the combined means consisted of markers for all four QTLs (Snn2, Tsn1, $X f c p 13$, and $X g d m 125)$ and explained $60 \%$ and $74 \%$ of the variation, respectively.

No significant epistatic interactions were detected among the markers underlying the QTLs (Snn2, Tsn1, Xfcp13, and $X g d m 125)$. However, the two QTLs associated with Snn2 and Tsn 1 both had significant additive effects for all three replicates as well as for the combined phenotypic means (Table 5). This reflects the significant differences in disease development among $\mathrm{RI}$ lines that have only Snn2 or Tsn 1 compared to those that have both genes as described above and shown in Table 4.

\section{Initial characterization of SnTox2}

Active SnTox2 samples treated with Pronase at a final concentration of $2 \mathrm{U} \mu \mathrm{I}^{-1}$ and incubated at $21^{\circ} \mathrm{C}$ for $4 \mathrm{~h}$, as well as Pronase alone, had no toxic activity on the RI line BG223, which was sensitive to SnTox2 but not SnToxA and therefore chosen as a differential genotype. Control samples not treated with Pronase showed necrosis (Figure 1). In light dependency experiments, plants placed in a $12 \mathrm{~h}$ photoperiod showed necrosis within 24-48 h, whereas plants placed in the dark showed no necrosis after $48 \mathrm{~h}$ (Figure 1).

Active SnTox2 samples that were passed through $30 \mathrm{kDa}$ and $10 \mathrm{kDa}$ filters showed activity on the SnTox2-sensitive wheat genotype BG223, whereas samples filtered through a $3 \mathrm{kDa}$ filter showed no toxic activity on BG223 (Figure 1). Size exclusion chromatography indicated that the toxin had a molecular weight slightly larger than aprotinin $(6.5 \mathrm{kDa})$ and Ptr ToxB (6.6 kDa) (Strelkov et al., 1999).

\section{Discussion}

The wheat-S. nodorum host-pathogen system is reminiscent of a classical gene-for-gene system (Flor, 1956) in which an elicitor protein produced by the pathogen interacts directly or indirectly with a host resistance gene product, leading to a necrotic hypersensitive response (HR) involving pro- grammed cell death (PCD) (Hammond-Kosack and Jones, 1996). The data presented here and previously (Friesen et al., 2006; Liu et al., 2004a,b, 2006) demonstrate that the SNB system employs elicitor-like proteins (toxins) that induce necrosis when interacting directly or indirectly with specific host gene products to induce a spreading necrosis (susceptibility) rather than HR-associated resistance.

We previously identified the proteinaceous HSTs SnToxA and $S$ Tox 1 produced by $S$. nodorum and showed that they interact with the host genes Tsn 1 and Snn1, respectively, to induce necrosis and thereby aid the fungus in causing disease (Friesen et al., 2006; Liu et al., 2004a,b, 2006). Here, we identify a third toxin, SnTox2, and the corresponding host sensitivity gene Snn2, and show that a compatible SnTox2-Snn2 interaction plays a major role in disease development similar to what we have shown for the SnTox1-Snn 1 (Liu et al., 2004a,b) and SnToxA-Tsn 1 (Friesen et al., 2006; Liu et al., 2006) interactions. Therefore, there are multiple gene-for-gene type HST-host receptor interactions involving different HSTs corresponding to specific host gene products present in the wheat-S. nodorum pathosystem that are highly important for the development of SNB. Although not the case for the ToxA-Tsn 1 interaction, it is possible that the SnTox2-Snn2 interaction is the result of multiple protein interactions specifically multiple toxic components. However, this seems unlikely because no evidence for multiple toxic components has been found in any of the purification steps for any of the three HSTs in this system, nor has it been shown for proteinaceous HSTs in other systems (Strelkov et al., 1999; Tomás et al., 1990). Isolation and characterization of each of the toxins is necessary and will clarify how this interaction is carried out.

This inverse gene-for-gene model has also been shown for the $P$. tritici-repentis-wheat pathosystem (Lamari et al., 2003) where HSTs including ToxA are involved in disease development. Although there is a distinct gene-for-gene relationship involving an HST interacting with a host sensitivity gene product, this interaction differs from a classical gene-for-gene interaction in that the toxins tend to act as virulence factors with additive effects that result in increased disease especially as it relates to lesion size. This is evidenced by the significant average reaction type difference between lines sensitive to SnToxA (1.91) or SnTox2 (2.30) only and lines sensitive to both toxins (3.07) (Figure 4, Table 4). The additive difference is illustrated by histograms of the average disease reaction types of the different genotypic classes in Figure 4. This figure illustrates how the average disease reaction type, which is based primarily on lesion size, increases when additional host-toxin interactions are present. This result is in contrast to classical $R$ gene-Avr gene interactions where the presence of multiple Avr genes interacting with their corresponding $\mathrm{R}$ genes produces a similar resistance response as that for a single $R$ gene-Avr gene interaction (Flor, 1956). 
Although none of the SnTox2 sensitive lines showed high levels of resistance (0-1), two lines sensitive to SnToxA showed average disease reaction types of less than 1 . These two lines contained BR34 alleles for QTLs QSnb.fcu-1BS and QSnb.fcu-5AL. These minor QTLs in combination with other potentially undetected minor QTL could result in a toxin sensitive genotype that is resistant to SNB. This would suggest that other resistance mechanisms not associated with toxin sensitivity may be effective at circumventing toxin production possibly by inhibition of penetration, or proliferation immediately after penetration. This increased level of resistance does not appear to correlate with sensitivity to the toxin as the toxin reactions are unambiguous, therefore mechanisms affecting the fungus must be involved.

The secondary/asexual cycles of this disease require the production of asexual pycnidia throughout the lesion. Pycnidiospores emerge from the pycnidia and are splash dispersed to the newly emerging plant parts (Solomon et al., 2006), and the cycle is repeated. Highly susceptible plants develop larger lesions with additional space for pycnidiospore production, and therefore secondary disease cycles with the potential for more impact on the newly emerging leaves and heads (Friesen et al., 2006; Liu et al., 2004a Liu et al., 2004b, 2006). Our work shows that this disease cycle is directly influenced by the compatible interaction between toxins and their corresponding host sensitivity genes (Figure 4). This influence is due to the fact that HSTs, in the presence of host sensitivity, affect lesion development, specifically lesion size. The identification of HSTs produced by $S$. nodorum and the corresponding host sensitivities in wheat are critical elements of the epidemiology of this disease. Control of SNB must take into account the virulence of the fungus as well as the resistance/susceptibility of the host to better combat this important disease of wheat.

Two of the four QTLs associated with resistance to SNB caused by isolate $\mathrm{Sn} 6$ were due to the effects of loci conferring insensitivity to SnToxA and SnTox2. The snn2 and tsn 1 alleles were responsible for conditioning the resistance effects of $0 S n b . f c u-2 D S$ and $O S n b . f c u-5 B L$, respectively (Figure 5). OSnb.fcu-2DS accounted for as much as $49 \%$ of the variation and $0 S n b . f c u-5 B L$ accounted for as much as $20 \%$ (Table 5 ), whereas in a previous study using the same host population with a different $S$. nodorum isolate, Tsn 1 accounted for $62 \%$ of the disease phenotype and the Snn2 locus was not significantly associated with disease (Liu et al., 2006). There are two possible explanations for this. The first is that some isolates produce relatively more of one toxin than the other in planta. Higher levels of SnTox2 production compared to SnToxA would result in the Snn2 locus having a stronger association with the disease phenotype compared to Tsn1. The second scenario is that there is a distinct race structure where each toxin is not produced by all isolates. For instance, Friesen et al. (2006) showed that the ToxA gene was found in only $5 \%$ of 91 isolates collected from China whereas it was found in $100 \%$ of the 58 isolates collected from Australia, indicating the potential for a race structure. The purification of the toxins and the cloning of the underlying genes will allow for the molecular analysis of toxin gene presence and expression and lead to a better understanding of disease progression as dictated by different toxins. Once the genes responsible for toxin production are identified and more is known about toxin production, it may be practical to propose a race structure for this fungus.

The two QTLs QSnb.fcu-1BS and QSnb.fcu-5AL (Figure 5) did not coincide with known toxin sensitivity loci. However, Liu et al. (2006) identified the QTL OSnb.fcu-1BS as being significantly associated with resistance to SNB caused by the isolate Sn2000, and Faris and Friesen (2005) identified QTLs in the same genomic regions on chromosomes $1 \mathrm{~B}$ and $5 \mathrm{~A}$ for resistance to tan spot in the same population. It is possible that the resistance effects of $0 S n b . f c u-1 B S$ and $Q S n b . f c u-5 A L$ are due to a general non-pathogen specific resistance mechanism, which would indicate that factors in addition to toxin insensitivity are involved in conferring complete resistance. It is also possible that isolate Sn6 produced additional yet unidentified toxins in planta, which caused the effects of the $1 B$ and $5 A$ QTLs.

With the exception of the studies by Liu et al. (2004b, 2006 , other attempts to identify QTL associated with SNB leaf and glume blotch resistance have employed either natural field infestation (Schnurbusch et al., 2003) or a mixture of a large number of isolates (Aguilar et al., 2005; Arseniuk et al., 2004; Czembor et al., 2003). Our preliminary data indicate that, in addition to SnToxA, SnTox1, and SnTox2, several other toxins are produced by different isolates of $S$. nodorum, and various isolates produce multiple toxins that may be expressed at varying levels (Friesen et al. unpubl. data). Therefore, while utilization of multiple isolate mixtures may be useful for the identification of broad-spectrum SNB resistance QTL, such studies are likely to be confounded by the presence of numerous toxins produced by different isolates. The production of multiple toxins by a mixed inoculum may make it difficult to measure the effects of sensitivity loci that govern specificity to individual toxins.

We have shown SnTox2 to be host-selective in nature and in the size range of previously reported proteinaceous HSTs. Ultra filtration indicated that this toxin is between 3 and $10 \mathrm{kDa}$ in size, and size exclusion chromatography showed it to migrate slightly before Aprotinin (6.5 kDa) and Ptr ToxB (6.6 kDa) (Strelkov et al., 1999), therefore SnTox2 is likely to be in the $7-10 \mathrm{kDa}$ range, however because of the limitations of size identification of small proteins using size exclusion chromatography this is not an extremely reliable estimation of size and is only being proposed as a rough estimation. 
Whereas little is known about the modes of action of SnTox1 and SnTox2, more work has been performed to determine the mode of action of Ptr ToxA in P. triticirepentis because only recently was it discovered that the ToxA gene was transferred from $S$. nodorum to $P$. triticirepentis (Friesen et al., 2006). In genotypes harboring the Tsn 1 allele, Ptr ToxA traverses the plant plasma membrane from the apoplastic space to the interior of the plant cell (Manning et al., 2007), possibly by receptor-mediated endocytosis. From there, Ptr ToxA is compartmentalized and localized to the chloroplast (Manning and Ciuffetti, 2005). Manning et al. (2007) recently showed that ToxA, once internalized, binds to a chloroplast protein designated ToxABP1. ToxABP1 was shown to have similarity to animal proteins involved in endocytosis and is found in both ToxA sensitive and insensitive wheat lines. In addition to light dependency (Manning and Ciuffetti, 2005), ToxA-induced PCD is also temperature-dependent and requires active host metabolism, transcription, and translation, as well as a host signaling mechanisms (Kwon et al., 1998; Rasmussen et al., 2004). Other studies of PCD induced by fungi with a necrotrophic phase have also been shown (Keon et al., 2007) and others have indicated that light is an important component in PCD leading to resistance as well as susceptibility (Keon et al., 2007; Montillet et al., 2005). In this study we have shown that SnToxA and SnTox2-induced necrosis are both light dependant similar to PCD induced by other pathogens (Montillet et al., 2005). Although speculative, it is possible that $S$. nodorum toxins are utilizing a resistance mechanism to induce necrosis leading to susceptibility by turning the host against itself similar to that proposed in the $M$. graminicola-wheat pathosystem (Keon et al., 2007). The identification of three toxin-host gene interactions including SnTox1 (Friesen et al. unpubl. data) SnToxA, and SnTox2 that rely on light for compatibility suggests that the toxins could be utilizing the same, or a similar, host mechanism to induce cell death. On the contrary, the additive effects of Snn2 and Tsn 1 in susceptibility could indicate two different mechanisms at work. Further investigation on the pathway or pathways involved in host sensitivity/susceptibility will be required to confirm or refute either hypothesis.

Differences in reaction to ToxA of insensitive and sensitive wheat genotypes are likely due to differences in the ability of the toxin to be internalized in the plant cell. Manning and Ciuffetti (2005) used biolistic bombardment of a GFP-ToxA fusion protein to show that insensitive genotypes developed necrosis if the toxin was internalized. Therefore, the genes conferring insensitive/sensitive reactions, such as Tsn1, Snn1, and Snn2, are likely involved in toxin recognition and act as gates for internalization. It is highly likely that these genes serve functions other than to confer toxin sensitivity and, as mentioned above, the toxins are possibly a result of evolutionary events to exploit basic plant func- tions. The map-based cloning of Tsn1 and Snn1 is in progress (Lu and Faris, 2006; Lu et al., 2006; Faris et al. unpubl. data). Once the genes governing host sensitivity are cloned, questions regarding host recognition of the toxin, mechanisms of toxin internalization, and subsequent interactions and events can be addressed.

Whereas the three $S$. nodorum toxins reported to date share the feature of dependency on light to cause cell death and possibly exploit the same host mechanism, we have identified additional $S$. nodorum toxin-host gene interactions that do not require light to cause cell death (Friesen et al., unpubl. data). Therefore, the $S$. nodorum pathogen not only produces multiple toxins, but likely different kinds of toxins that exploit different host mechanisms. Future work will focus on the identification and characterization of toxin-host gene interactions that differ in their underlying mechanisms to cause cell death.

This work defines the wheat-SNB toxin system as a potential model inverse gene-for-gene system. Because of the availability of the complete $S$. nodorum genomic sequence and the fact that all HSTs identified in this system have been proteinaceous in nature, this system has the potential to become a model in the discovery of how toxin-producing necrotrophic fungi induce disease. Furthermore, because these toxins are primary gene products, countless possibilities exist for the investigation of the evolution of this host-pathogen system using gene sequence analysis.

\section{Experimental procedures}

\section{Plant materials}

A segregating population of $\mathrm{RI}$ lines derived from a cross between the Brazilian hard red spring wheat (HRSW) breeding line BR34 and the North Dakota HRSW variety 'Grandin' was obtained from Dr James A. Anderson, University of Minnesota. The BG mapping population consists of $118 \mathrm{~F}_{7: 9}$ lines, with BR34 being highly resistant to SNB (average disease reaction 0.17 ) and Grandin being susceptible (average disease reaction 4.0) (Table 4). In addition, three $F_{1}$ plants and an $F_{2}$ population consisting of 38 individuals derived from $B R 34 \times$ Grandin was used to determine gene action of toxin sensitivity. BG RI lines BG261 and BG223 were used as differential lines for toxin sensitivity experiments. BG261 is sensitive to SnToxA only whereas BG223 is sensitive to SnTox2 only.

\section{Fungal cultures, culture filtrate production, toxin partial purification, and ToxA gene verification}

The S. nodorum isolate Sn6, which was collected from wheat in North Dakota, USA was used for all culture filtrate production and inoculation experiments. Culture filtrates of $S$. nodorum were produced as previously described (Liu et al., 2004a). Toxin was extracted from Sn6 culture filtrates that had been grown for 3 weeks, also as described in Liu et al. (2004a). Culture filtrates were filter sterilized using a $0.2 \mu \mathrm{m}$ filter and dialyzed overnight against a $20 \mathrm{~mm}$ sodium acetate buffer $\mathrm{pH} 5$, using $3.5 \mathrm{kDa}$ molecular weight 
cutoff dialysis tubing. In an attempt to partially purify the toxin present in the culture filtrate, the dialyzed product was subjected to ion exchange chromatography on a $10 \mathrm{ml}(1.6 \times 5 \mathrm{~cm})$ S-Sepharose Fast Flow (Pharmacia) equilibrated with $20 \mathrm{~mm}$ sodium acetate, $\mathrm{pH}$ 5 , and eluted with a linear gradient from 0 to $350 \mathrm{~mm} \mathrm{NaCl}$ over ten column volumes. Active fractions were pooled and used to infiltrate differential lines within the BG population. In some experiments active fractions were concentrated approximately 10 fold by either ultrafiltration or acetone precipitation and samples were separated using a Superose 12 HR 10/30 column (Pharmacia) with a buffer of $20 \mathrm{~mm}$ sodium acetate, $150 \mathrm{~mm}$ sodium chloride, $\mathrm{pH} 5.0$, with a flow rate of $0.3 \mathrm{ml} \mathrm{min}^{-1}$. Samples were tested on lines BG261 and BG223 for SnToxA and SnTox2 activity, respectively.

Verification of the ToxA gene in isolate $\mathrm{Sn} 6$ was carried out by PCR amplification of a portion of the gene. Forward (5'-ACCGTCCGGCTACCTAGCAA- $3^{\prime}$ ) and reverse (5'-CGTTCCGGTTGTGCTCTCCT$\left.3^{\prime}\right)$ primers were designed and used to amplify a 965 bp fragment from the ToxA gene of Sn6 using both a genomic clone and isolate Sn2000 (Friesen et al., 2006) as positive controls.

\section{Preliminary characterization of the toxin}

The active fractions from ion exchange chromatography were treated with Pronase (EMD Biosciences, Inc., San Diego, CA, USA), a mixture of endo- and exo-proteinases, to identify whether this toxin was proteinaceous in nature. Pronase was added to active samples at a rate of $2 \mathrm{U} \mathrm{\mu l}^{-1}$ and incubated at $21^{\circ} \mathrm{C}$ for $4 \mathrm{~h}$ followed by infiltration into the SnTox2 sensitive wheat line BG223. The infiltration of samples not treated with Pronase and samples with Pronase alone were used as controls.

Evaluation of light dependency for necrosis production was evaluated by infiltrating individual plants of line BG223 with active SnTox2 fractions from ion exchange chromatography. Three replicates of three plants each were infiltrated with semi-purified SnTox2 and placed in treatments of either a $24 \mathrm{~h}$ dark or $12 \mathrm{~h}$ light$12 \mathrm{~h}$ dark photoperiod both at $21^{\circ} \mathrm{C}$.

To establish the approximate size of the toxin, active culture filtrates containing SnTox2 were subjected to size-based ultrafiltration using 3, 10, and $30 \mathrm{kDa}$ cutoff filters (Millipore, Billerica, MA USA). Samples of concentrates and filtrates were evaluated using a plant bioassay as described below to determine which cutoff filter(s) retained the toxin and to estimate the approximate size of the toxin. To obtain a more refined measurement of the toxin's size, crude culture filtrates were concentrated approximately 10 fold by either ultrafiltration or acetone precipitation and $0.5 \mathrm{ml}$ samples were separated using a Superose 12 HR 10/30 column (Pharmacia) with a buffer of $20 \mathrm{~mm}$ sodium acetate, $150 \mathrm{~mm}$ sodium chloride, $\mathrm{pH} 5.0$, and at a flow rate of $0.3 \mathrm{ml} \mathrm{min}^{-1}$. Fractions were assayed on the SnTox2 differential line BG223 for SnTox2 activity. Known size standards were used for column calibration. These standards include carbonic anhydrase (29 kDa) Myoglobin (17 kDa) Horse heart Cytochrome $C(12.5 \mathrm{kDa}) \operatorname{Ptr}$ ToxB $(6.6 \mathrm{kDa})$ and Aprotinin $(6.5 \mathrm{kDa})$. Fractions were then bio-assayed as described below.

\section{Toxin bioassays}

A bioassay was used to characterize the response of wheat lines to the semi-purified SnTox2 produced by isolate Sn6 based on the development of necrosis (Figure 1) (Liu et al., 2004a). Approximately $25 \mu \mathrm{l}$ of semi-purified active product was infiltrated into a fully expanded secondary leaf using a $1-\mathrm{ml}$ syringe with the needle removed. The boundaries of the infiltration site were marked before water-soaking disappeared. After infiltration, all plants were moved to a growth chamber at $21^{\circ} \mathrm{C}$ with a $12-\mathrm{h}$ photoperiod. Leaves were evaluated 3 days after infiltration and scored as insensitive or sensitive. Sensitive reactions were characterized by visible necrosis whereas insensitivity was indicated when no reaction occurred within the infiltrated area (Figure 1). All experiments were replicated at least twice.

\section{Conidial inoculations}

For disease evaluation, individual lines of the BG population were inoculated with conidia of Sn6. Individual lines of the BG population were planted along with parents using three conetainers (Stuewe and Sons, Inc., Corvallis, OR, USA) per line and three plants per conetainer. Therefore, nine plants were evaluated collectively for each individual replicate. Plants were placed in racks of 98 consisting of 20 lines, bordered with the wheat cultivar Grandin to eliminate edge effects and each replicate was given a unique randomization. Methods for producing inoculum and inoculating plants were carried out as described in Liu et al. (2004b). Plants were inoculated at the two-to-three-leaf stage. Following inoculation, plants were placed in $100 \%$ relative humidity at $21^{\circ} \mathrm{C}$ for $24 \mathrm{~h}$, and then placed in a controlled chamber under a $12 \mathrm{~h}$ photoperiod at $21^{\circ} \mathrm{C}$. Disease ratings were carried out at $7 \mathrm{~d}$ post-inoculation by scoring lesions on the second leaf using the $0-5$ scale described by Liu et al. (2004b). Three randomized replicates were completed for the entire population along with parental lines.

\section{Molecular mapping and QTL analysis}

Over 700 molecular markers have been mapped in the BG population and details regarding marker development, map construction, and analysis were presented in Liu et al. (2005). The Tsn 1 locus was mapped in the BG population by Liu et al. (2005) using Ptr ToxA and more recently, Liu et al. (2006) assessed the population for reaction to SnToxA and showed that reactions to both Ptr ToxA and SnToxA co-segregate at the Tsn 1 locus. Reactions of RI lines to the Sn6 toxin preparations were assigned genotypic values and assessed for linkage to other markers in the dataset using the 'TRY' command of the computer program MAPMAKER v.2.0 for Macintosh (Lander et al., 1987).

The BG population was previously used to detect QTLs associated with tan spot resistance (Faris and Friesen, 2005), resistance to SNB caused by isolate Sn2000 (Liu et al., 2006), and plant height and days to heading (Liu et al., 2005). The methods used for QTL detection in this experiment were essentially the same as described in the previous studies. Briefly, simple linear regression was used to identify markers significantly $(P<0.001)$ associated with resistance to SNB isolate Sn6 using the computer program MAP MANAGER OTX (Manly et al., 2001). Interval regression mapping (simple and composite) was performed using a subset of 354 markers spaced approximately $10-20 \mathrm{cM}$ apart to evaluate marker intervals associated with resistance. A critical LOD threshold of 3.2 was established by executing a permutation test with 5,000 permutations. The $95 \% \mathrm{Cl}$ for each QTL were established by bootstrapping. Markers with significant main effects were assembled into a multiple regression model to determine the proportion of the total phenotypic variation explained by the markers. Markers with significant main effects were tested for significant interactions $(P<0.001)$ with each other. Additive effects of QTLs were determined with the MAP MANAGER OTX software package (Manly et al., 2001). 


\section{Statistical analysis}

Statistical analysis was carried out using the SAS software package (SAS Institute, Inc. Version 9.1) SAS Institute Inc., 2006. Analysis of variance was calculated using the PROC GLM procedure of SAS using the combined lesion type means derived from the three replicates. A test for homogeneity among replicates was conducted to identify significant differences among reps at the 0.05 and 0.01 levels of probability. Mean separation for the genotypic means was determined by the use of Fisher's protected least significant difference (LSD) at $\alpha=0.05$.

\section{Acknowledgements}

The authors thank Danielle Holmes and Philip Meyer for technical assistance and Dr. Steven S. Xu for assistance with statistical anaIysis. This research was supported by USDA-ARS CRIS projects 5442-22000-037-00D and 5442-22000-030-00D.

\section{References}

Aguilar, V., Stamp, P., Winzeler, M., Winzeler, H., Schachermayr, G., Keller, B., Zanetti, S. and Messmer, M.M. (2005) Inheritance of field resistance to Stagonospora nodorum leaf and glume blotch and correlations with other morphological traits in hexaploid wheat (Triticum aestivum L). Theor. Appl. Genet. 111, 325-336.

Arseniuk, E., Czembor, P.C., Czaplicki, A., Song, Q., Cregan, P.B., Hoffman, D.L. and Ueng, P.P. (2004) QTL controlling partial resistance to Stagonospora nodorum leaf blotch in winter wheat cultivar Alba. Euphytica 137, 225-231.

Czembor, P.C., Arseniuk, E., Czaplicki, A., Song, Q.J., Cregan, P.B. and Ueng, P.P. (2003) QTL mapping of partial resistance in winter wheat to Stagonospora nodorum blotch. Genome 46, 546-554.

Endo, T.R. and Gill, B.S. (1996) The deletion stocks of common wheat. J. Hered. 87, 295-307.

Faris, J.D. and Friesen, T.L. (2005) Identification of quantitative trait loci for race-nonspecific resistance to tan spot of wheat. Theor Appl. Genet. 111, 386-392.

Flor, H.H. (1956) The complementary genetic systems in flax and flax rust. Adv. Genet. 8, 29-54.

Friesen, T.L., Stukenbrock, E.H., Liu, Z.H., Meinhardt, S.W., Ling, H., Faris, J.D., Rasmussen, J.B., Solomon, P.S., McDonald, B.A and Oliver, R.P. (2006) Emergence of a new disease as a result of interspecific virulence gene transfer. Nat. Genet. 38, 953956.

Hammond-Kosack, K.E. and Jones, J.D.G. (1996) Resistance genedependent plant defense response. Plant Cell, 8, 1773-1791.

Keon, J., Antoniw, J., Carzaniga, R., Deller, S., Ward, J.L., Baker, J.M., Beale, M.H., Hammond-Kosack, K. and Rudd, J.J. (2007) Transcriptional adaptation of Mycosphaerella graminicola to programmed cell death (PCD) of its susceptible wheat host. Mol. Plant Microbe Interact. 20, 178-193.

King, J.E., Cook, R.J. and Melville, S.C. (1983) A review of Septoria diseases of wheat and barley. Ann. Appl. Biol. 103, 345-373.

Kwon, C.Y., Rasmussen, J.B. and Meinhardt, S.W. (1998) Activity of Ptr ToxA from Pyrenophora tritici-repentis requires host metabolism. Physiol. Mol. Plant Pathol. 52, 201-212.

Lamari, L., Strelkov, S.E., Yahyaoui, A. and Smith, R.B. (2003) The identification of two races of Pyrenophora tritici-repentis from the host center of diversity confirms a one-to-one relationship in tan spot of wheat. Phytopathology, 93, 391-396.
Lander, E.S., Green, P., Abrahamson, J., Barlow, A., Daly, M.J., Lincoln, S.E. and Newberg, L. (1987) MAPMAKER: an interactive computer package for constructing primary genetic linkage maps of experimental and natural populations. Genomics, 1, 174-181.

Liu, Z.H., Faris, J.D., Meinhardt, S.W., Ali, S., Rasmussen, J.B. and Friesen, T.L. (2004a) Genetic and physical mapping of a gene conditioning sensitivity in wheat to a partially purified hostselective toxin produced by Stagonospora nodorum. Phytopathology, 94, 1056-1060.

Liu, Z.H., Friesen, T.L., Meinhardt, S.W., Ali, S, Rasmussen, J.B. and Faris, J.D. (2004b) Quantitative trait loci analysis and mapping of seedling resistance to Stagonospora nodorum leaf blotch in wheat. Phytopathology, 94, 1061-1067.

Liu, Z.H., Anderson, J.A., Hu, J., Friesen, T.L., Rasmussen, J.B. and Faris, J.D. (2005) A wheat intervarietal genetic linkage map based on microsatellite and target region amplified polymorphism markers and its utility for detecting quantitative trait loci. Theor. Appl. Genet. 111, 792-794.

Liu, Z.H., Friesen, T.L., Ling, H., Meinhardt, S.W., Oliver, R.P., Rasmussen, J.B. and Faris, J.D. (2006) The Tsn 1-ToxA interaction in the wheat-Stagonospora nodorum pathosystem parallels that of the wheat-tan spot system. Genome, 49, 1265-1273.

Lu, H.J. and Faris, J.D. (2006) Macro- and micro-colinearity between the genomic region of wheat chromosome $5 \mathrm{~B}$ containing the Tsn1 gene and the rice genome. Funct. Integr. Genomics, 6, 90103.

Lu, H.J., Fellers, J.P., Friesen, T.L., Meinhardt, S.W. and Faris, J.D. (2006) Genomic analysis and marker development for the Tsn1 locus in wheat using bin-mapped ESTs and flanking BAC contigs. Theor. Appl. Genet. 112, 1132-1142.

Manly, K.K. Jr, Cudmore, H.H. and Meer, J.M. (2001) Map Manager QTX, cross platform software for genetic mapping. Mam. Gen. 12, 930-932.

Manning, V.A. and Ciuffetti, L.M. (2005) Localizatin of Ptr ToxA produced by Pyrenophora tritici-repentis reveals protein import into wheat mesophyll cells. Plant Cell, 17, 3203-3212.

Manning, V.A., Hardison, L.K. and Ciuffetti, L.M. (2007) Ptr ToxA interacts with a chloroplast-localized protein. Mol. Plant Microbe Interact. 20, 168-177.

Montillet, J-L., Chamnongpol, S., Rustérucci, C., Dat, J., van de Cotte, B., Agnel, J-P., Battesti, C., Inzé, D., Van Breusegem, F. and Triantaphylidès, C. (2005) Fatty Acid Hydroperoxides and $\mathrm{H}_{2} \mathrm{O}_{2}$ in the Execution of Hypersensitive Cell Death in Tobacco Leaves. Plant Physiol. 138, 1516-1526.

Rasmussen, J.B., Kwon, C.Y. and Meinhardt, S.W. (2004) Requirement of host signaling mechanisms for the action of Ptr ToxA in wheat. Eur. J. Plant Pathol. 110, 333-335.

SAS Institute Inc. (2006). SAS/STAT User's Guide, Version 9.1. SAS Publishing, Cary, NC.

Schnurbusch, T., Paillard, S., Fossati, D., Messmer, M., Schachermayr, G., Winzeler, M. and Keller, B. (2003) Detection of QTLs for Stagonospora glume blotch resistance in Swiss winter wheat. Theor. Appl. Genet. 107, 1226-1234.

Solomon, P.S., Wilson, T.J.G., Rybak, K., Parker, K., Lowe, R.G.T. and Oliver, R.P. (2006) Structural characterisation of the interaction between Triticum aestivum and the dothideomycete pathogen Stagonospora nodorum. Eur. J. Plant Pathol. 114 275-282.

Sourdille, P., Singh, S., Cadalen, T., Brown-Guedira, G.L., Gay, G. Qi, L.L., Gill, B.S., Dufour, P., Murigneux, A. and Bernard, M. (2004) Microsatellite-based deletion bin system for the establishment of genetic-physical map relationships in wheat (Triticum aestivum L.). Funct. Integr. Genomics, 4, 12-25. 
Strelkov, S.E., Lamari, L. and Ballance, G.M. (1999) Characterization of a host-specific protein toxin (Ptr ToxB) from Pyrenophora tritici-repentis. Mol. Plant Microbe Interact. 12, 728-732.

Tomás, A., Feng, G.H., Reeck, G.R., Bockus, W.W. and Leach, J.E. (1990) Purification of a cultivar-specific toxin from Pyrenophora tritici-repentis, causal agent of tan spot of wheat. Mol. Plant Microbe Interact. 3, 221-224.
Wicki, W., Winzeler, M., Schmid, J.E., Stamp, P. and Messmer, M. (1999) Inheritance of resistance to leaf and glume blotch caused by Septoria nodorum Berk. in winter wheat. Theor. Appl. Genet. 99, 1265-1272.

Wolpert, T.J., Dunkle, L.D. and Ciuffetti, L.M. (2002) Host-selective toxins and avirulence determinants: what's in a name. Annu. Rev. Phytopathol. 40, 251-285. 